\title{
Reporting Sick: Are Sporting Events Contagious?
}

\author{
Peter Skogman Thoursie*†
}

February 8, 2002

\begin{abstract}
Moral hazard is easy to justify theoretically but difficult to detect empirically. Individuals may report sick due to illness as well as for moral hazard reasons. Potential abuse of the sickness insurance system in Sweden is estimated by comparing the change between the number of men and women who report sick during a popular sporting event and a preceding time period. Differencein-difference estimates provide clear evidence that the number of men who reported sick increased in order to watch the sporting event on television.
\end{abstract}

Keywords: Reporting sick, Moral hazard, Difference-in-difference JEL: J22;J29

${ }^{*}$ Department of Economics, Stockholm University and National Social Insurance Board, Sweden. Corresponding address: Department of Economics, Stockholm University, SE-106 91 Stockholm, Sweden. E-mail: peter.thoursie@ne.su.se.

${ }^{\dagger}$ I would like to thank Mahmood Arai, Julie Sundqvist, Joakim Söderberg and Björn Öckert for valuable comments. Joakim Söderberg also provided invaluable help in obtaining data. I have also benefited from comments by participants in seminars at the Department of Economics and SOFI, Stockholm University. 


\section{Introduction}

Moral hazard is a well-known problem in economic theory but difficult to prove empirically. The main obstacle is to find an exogenous source of variation in the measure which represents individual behavior when seeking to explain the outcome. In the case of changes in absence from work due to illness, it is difficult to separate a change in health effects from changes in other variables. Health varies cyclically and is correlated with e.g. industry affiliation, work environment, labor-market conditions, type of employment contract and labor income. Changes in these variables can also explain absence due to illness. ${ }^{1}$

Abuse of the sickness insurance system could be an important explanatory factor underlying changes in reporting sick. The objective of this paper is to estimate potential existence of such abuse. To my knowledge, no previous study has estimated this behavior in a causal manner. Absence due to illness is pro-cyclical. In the case of Sweden, 25 sick days were reported per capita when the economy peaked in 1988. As of 2001, sick days per capita have returned to about the same high levels as in 1988. The procedure for reporting sick is simple; it only requires a phone call to one's workplace - a doctor's certificate is not necessary until the seventh day.

In the study reported here, I use the incidence of popular sporting events broadcasted on television during regular working hours or at night as quasi-experiments. The hypothesis that men report sick in order to watch sports during working hours is tested by comparing the change in the number of men and women who report sick between the sporting event and a preceding time period. Women are used as the comparison group because empirical evidence suggests that men watch sports on

\footnotetext{
${ }^{1}$ Barmby et al. (1991, 1995), Brown et al. (1999), Winkelmann (1999) and Arai \& Skogman Thoursie (2001) have found that the terms of employment contracts are important in explaining absence. For a more extensive discussion of variables explaining absence due to sickness, see e.g. Brown \& Sessions (1996), Johansson \& Palme (1996) and Lidwall \& Skogman Thoursie (2000).
} 
television more than women do (see Abrahamsson (1990)). This makes it possible to control for all gender-specific factors such as occupational status, health status, work environment and labor-market conditions, as well as all symmetric seasonal factors such as a potential influenza epidemic.

Traditional economic theory suggests that workers interested in watching sports on television have strong incentives to report sick if the value of watching a sporting event is higher than the cost of doing so. Most workers have a full-time contract implying a 40-hours work-week of approximately 8 hours a day, without the opportunity to freely allocate the working hours over a day or a week. Thus, the optimal amount of working hours might be lower than the contracted number of working hours, particularly during weeks when a sporting event is broadcasted on television during regular working hours. There are alternatives to reporting sick such as taking a day off or compensatory leave. Most workers, however, have a fixed number of yearly vacation days and taking one or several days off would reduce future available vacation time by the corresponding amount of days. Of course, the incentive to report sick in order to watch sports would decrease with the risk of being detected and the punishment associated with this risk.

The analysis is based on two popular sporting events that were broadcasted on television during regular working time or on radio during nights. The first event was a World Championship cross-country skiing competition (30 kilometers) in Oberstdorf, Germany, on February 12, 1987 and the second was the winter Olympic Games in Calgary, Canada, February 13-28, 1988. Broadcast times for both events were collected from old TV-magazines. This information was then combined with register data on the population of illness cases started in 1987 and 1988. The results show an increase in the number of days men reported sick during both events. A conservative calculation suggests male sick days due to the Calgary Games constituted 3.6 percent of all sick days 
reported during the time period when the Games took place.

The remainder of the paper is organized as follows. The criteria for treating popular sporting events as quasi-experiments are described in Section 2. The data are outlined in Section 3. The estimation results are reported in Section 4. Section 5 concludes.

\section{Popular events as quasi-experiments}

Several criteria have to be fulfilled when the incidence of an event is used as a quasi-experiment. First, the event has to affect the treatment group but not the comparison group. Second, the outcome of interest should generally develop similarly over time for the treatment and the comparison groups. This reduces the risk that unobserved group-specific factors of importance in explaining the outcome have developed differently for the treatment and the comparison groups. Otherwise, this will seriously bias the estimated impact of the event on the outcome. Third, the event under study should affect a clearly defined underlying population thereby making it easier to interpret the results.

Both of the sporting events mentioned in the Introduction fulfil these criteria. The World Championship skiing competition was directly broadcasted 10.55 a.m., i.e. during regular working hours. The winter Olympic Games were broadcasted live on the radio at nights.

Men, i.e. the treatment group, watch sports more than women do, and are therefore affected by the event, whereas women, who constitute the comparison group, are not. Both sporting events can be said to affect a substantial fraction of men in the sense that winter sports are extremely popular in Sweden. Many world-famous Swedish crosscountry skiers such as Gunde Svan and Thomas Wassberg, participated in Oberstdorf. These cross-country skiers, the ice-skater Thomas Gustavsson, the Swedish ice-hockey team - to mention a few-participated

in the Calgary Games. All of these teams and athletes were anticipated 
to be highly successful in both events. For these reasons, criteria one is most likely to be met.

The second criteria is also likely to be met because absence due to illness shows a similar development for men and women in general. Furthermore, both events took place during periods without dramatic seasonal variations in the outcome measure or erratic absence due to illness. This reduces the risk of capturing spurious changes in outcome for either of the groups. For example, it seemed important to avoid sporting events that took place during holidays, where absence due to illness show dramatic jumps. One explanation for this is that men and women are allocated differently across sectors. In some sectors, such as the care sector where women are overrepresented, workers are often required to work on holidays, implying that women are under a greater risk of reporting sick.

The third criteria is met since both sporting events took place during periods where sick leave is at relatively high levels. For example, using sporting events in the summer, when very few workers report sick, is problematic because the results would be based on a potentially selected sample. For this reason, an effect potentially obtained from the events chosen in this study can be interpreted in terms of a general behavioral effect.

The quasi-experimental design used here has some advantages compared to many other studies with an analogous design but applied to other issues. A common feature in earlier studies is that changes in outcome measures are compared over years or months. ${ }^{2}$ For this reason, there is always a risk that characteristics of the treatment and the comparison groups have developed differently over these periods. If these characteristics are crucial in explaining the outcome and the researcher

\footnotetext{
${ }^{2}$ Many studies have compared differences in post and pre-program yearly earnings between participants in labor-market programs and non-participants (see e.g. Ashenfelter (1978), Ashenfelter \& Card (1985)). For other studies with an analogous approach where changes in yearly outcome variables are used, see e.g. Card (1990), Card \& Krueger (1994), Meyer, Viscusi and Durbin (1995), Gruber (1996), Goldin \& Rouse (2000) and Angrist \& Lavy (2001).
} 
has no information on them, the results can be seriously biased. In this paper, changes in absence due to illness between two adjacent time periods are analyzed. Therefore, it is most unlikely that the unobserved characteristics of men and women developed differently during the specified periods.

\section{$3 \quad$ Data and empirical strategy}

The data used are from the Register of Cases Due to Illness collected by the Swedish National Social Insurance Board. The Register includes information on the start and end dates of all cases of illness as well as on sex and age. The skiing competition took place on a particular Thursday in 1987 and the winter Olympic Games took place during a two-week period in 1988. I therefore restricted the sample to the population of one-day and two-day cases of illness which started in 1987 and one-day to seven-day cases which started in 1988. The sample was further restricted to ages 20-64. ${ }^{3}$ Sample statistics for cases of illness which began in 1987 and 1988, respectively, are summarized in Table A1 in the Appendix.

When analyzing the effect of the sporting events on the number of men who reported sick, the sick rate is used as the outcome variable. The sick rate is defined as the share - in percent - of the number of cases of a specific length in relation to the total of employment in hundreds. ${ }^{4}$ For example, the male sick rate for one-day cases on the Oberstdorf Thursday is 6.55. This implies that $1,395(0.00655 \times 2,130,500)$ employed men reported one sick day on the Oberstdorf Thursday. That is, a total 2,130,500 men were employed in February 1987. Employment in

\footnotetext{
${ }^{3}$ In Sweden it is possible to receive partial sickness benefits. The sample here is restricted to the population with full-time sickness benefits.

${ }^{4} \mathrm{I}$ use the number of cases of illness in relation to employment in order to have a measure describing the risk of becoming sick. An unemployed person can report sick but the unemployment rates for men and women were at very low levels (about 2 percent) during 1987 and 1988. For unemployment figures, see Statistics Sweden $(1987,1988)$.
} 
hundreds is used simply to avoid even more decimals.

One-day and two-day cases of illness which started on the specific Thursday were used to analyze the skiing competition in Oberstdorf. Regarding the Calgary Games, one-day to seven-day cases which started on any day except Saturday and Sunday within a two-week period were used.

The development of the ratio between the male and female Thursday sick rates from the middle of January to the beginning of April in 1987 is reported in Figure 1 (the vertical line at 7 corresponds to the Oberstdorf Thursday). ${ }^{5}$ The ratio between male and female sick rates is rather constant over time. The exception is the Oberstdorf Thursday for oneday cases where the ratio seems to jump upwards. This implies that relative to women, there was an increase in the number of men who reported sick on this Thursday.

The development of the ratio between the male and female sick rates the first quarter of 1988 is reported in Figures 2a and 2b (the vertical line at 3 corresponds to the Calgary two-week period). ${ }^{6}$ For all lengths, the ratios are almost constant over time except for a jump during the the period of the Calgary Games. Again, relative to women, the number of men who reported sick seems to have increased during the Calgary Games.

To summarize, male and female sick rates developed similarly over time except during the two sporting events. In order to examine the apparent increase in the number of men who reported sick during the two events in more detail, I now turn to the statistical method applied in this study.

\footnotetext{
${ }^{5}$ The value 3 on the $\mathrm{x}$-axis represents Thursday, January 15 th, the value 4 Thursday, January 22nd and so on.

${ }^{6}$ The first two-week period is the second half of January, the second two-week period is the first half of February, etc.
} 


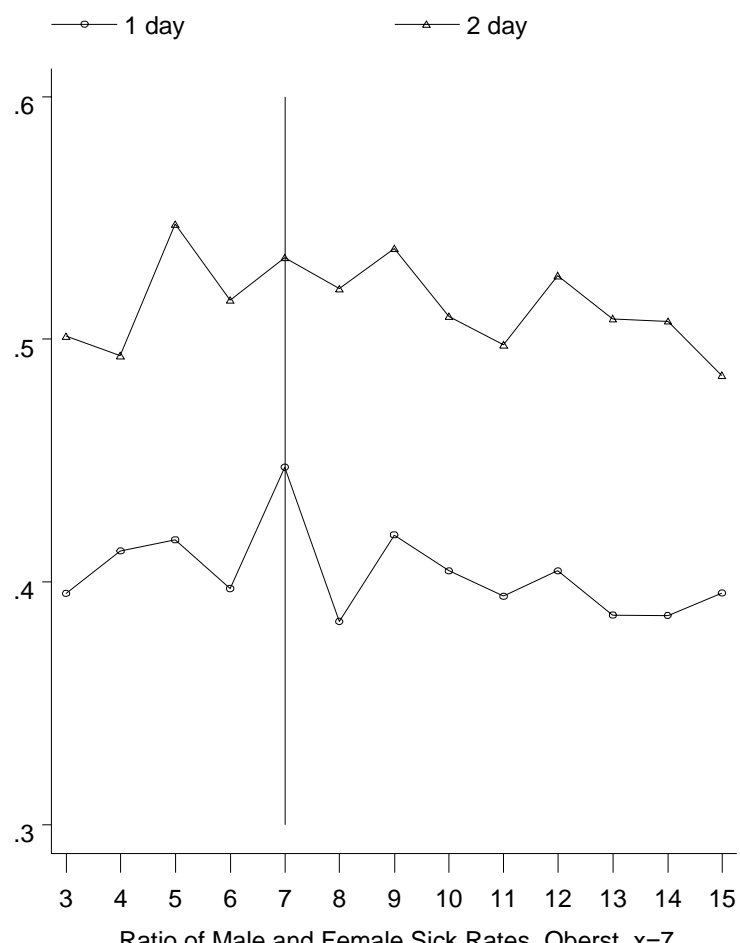

Ratio of Male and Female Sick Rates, Oberst. $x=7$

Figure 1

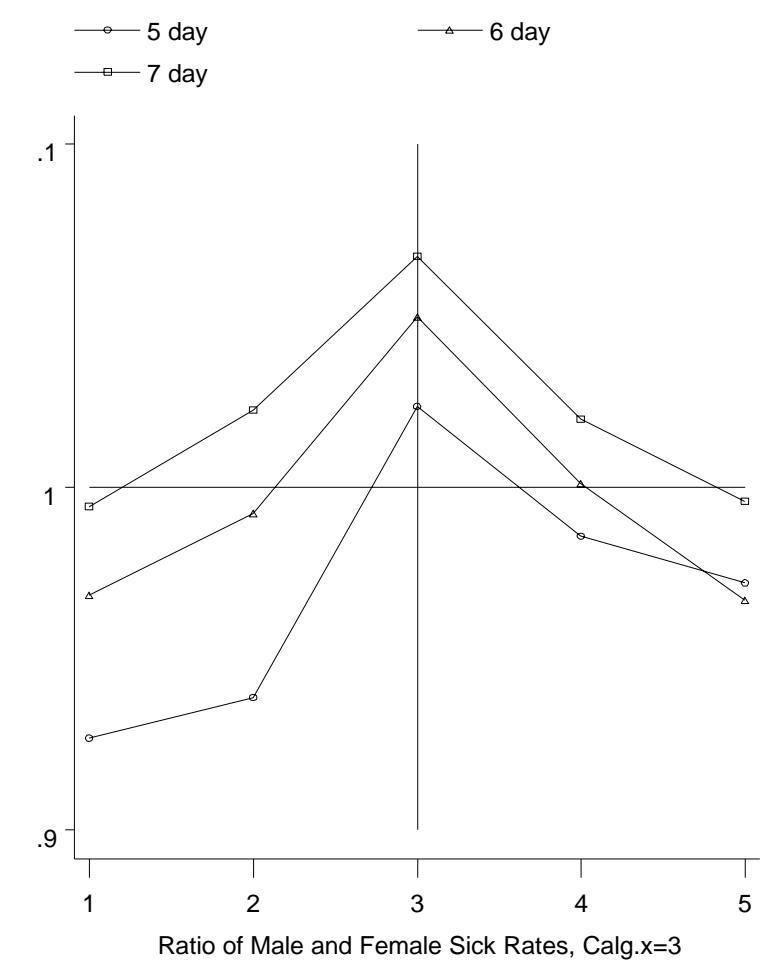

Figure $2 b$

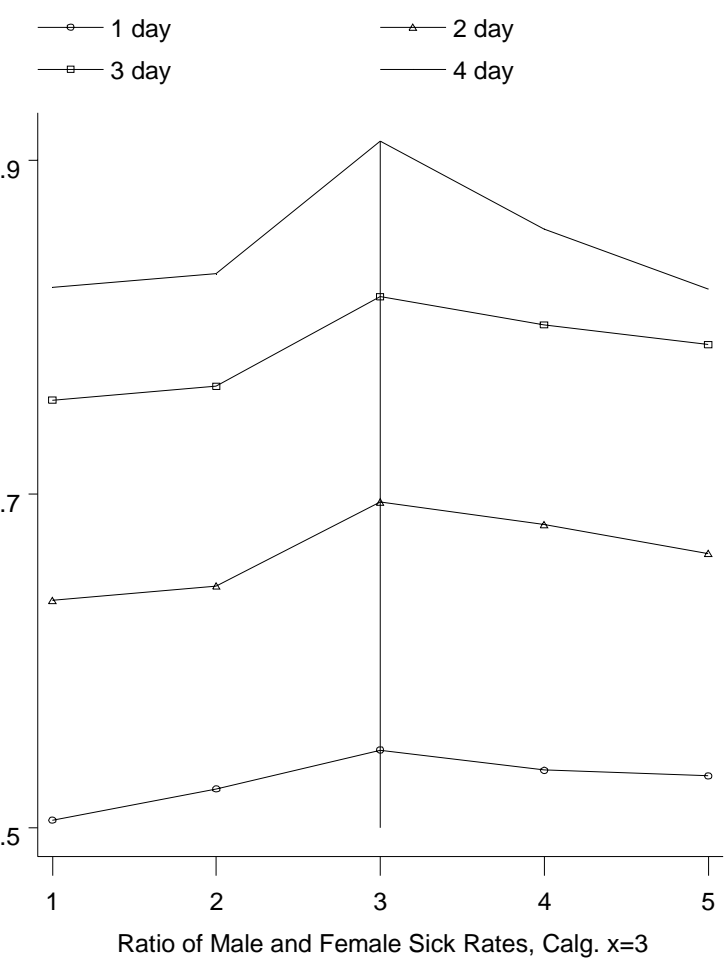

Figure 2a 
The simple model used here is based on the assumption that any differences in sick rates between men and women are fixed over time. Letting $Y_{i t}^{s}$ be a variable indicating whether any employed individual $i$ belonging to sex $s$ ( $s=M$ if male and $F$ if female) at time $t$ is reported sick, the regression model may be written as:

$$
Y_{i t}^{s}=\alpha+\beta d^{s}+\gamma d_{t}+\delta d_{t}^{s}+\varepsilon_{i t}^{s},
$$

where $d^{s}$ is a dummy variable taking the value 1 if the worker is a male $(0$ if female), $d_{t}$ is a dummy variable taking the value 1 if there is a popular sporting event at time $t$ ( 0 otherwise) and $d_{t}^{s}$ is a dummy variable taking the value 1 if there is a popular sporting event at time $t$ and if the worker is a male ( 0 otherwise). ${ }^{7} \varepsilon_{i t}^{s}$ is the disturbance term.

The casual effect of the sporting event on the behavior of men who report sick, assumed to be constant, is represented by $\delta$. The key identifying assumption is that $\delta$ would be zero in the absence of the event, or $E\left[\varepsilon_{i t}^{s} \mid d_{t}^{s}\right]=0$. This is likely to be the case since sick rates between two adjacent time periods are compared and any changes in gender-specific characteristics that are relevant in explaining absence due to illness are not likely to change over a very short time period such as from one week to another. The specification in equation (1) controls for all fixed gender differences, $d^{s}$, and all period-specific effects common to all individuals, $d_{t}$. Thus, while men may have lower sick rates than women, these differences are assumed to be due to differences in occupational status, work environment, etc. that can be regarded as permanent and have time-invariant effects on behavior related to reporting sick. Furthermore, potential time shocks such as the incidence of an influenza epidemic are captured by $d_{t}$ as long as they have a symmetric effect on men and women.

\footnotetext{
${ }^{7}$ Thus, $d_{t}^{s}$ is simply an interaction variable between the male dummy variable and time dummy variable representing the time when the sporting event took place.
} 
The casual effect of a popular sporting event is identified by comparing the change in male sick rates between the period of the event and the preceding period with the corresponding change in female rates. Denoting $t=p$ as the time period of the popular sporting event period ("period of sporting event") and $t=b$ as the period before the event ("before sporting event"), the expected change in male sick rates between these two periods and the corresponding change in female rates is:

$$
E\left[Y_{i p}^{M}-Y_{i b}^{M} \mid d^{s}=1\right]-E\left[Y_{i p}^{F}-Y_{i b}^{F} \mid d^{s}=0\right]=\delta .
$$

An unbiased estimate - the "difference-in-difference" estimator $(d d)$ of the event, $\delta$, is obtained by taking the sample analog of equation (2):

$$
\widehat{\delta}_{d d}=\Delta \bar{Y}^{M}-\Delta \bar{Y}^{F}=\bar{Y}_{p}^{M}-\bar{Y}_{b}^{M}-\left(\bar{Y}_{p}^{F}-\bar{Y}_{b}^{F}\right),
$$

where a bar indicates an average over individuals $i^{8}$

The method applied here does not estimate the relative change in reporting sick. The absolute change in reporting sick is estimated instead, which may be somewhat misleading. For example, if the difference-indifference estimate of the specific sporting event turns out to be zero, it might be the case that as compared to women, the number of men who reported sick increased more in relative terms because male sick rates are always at lower levels. Thus, the estimation technique applied here is a conservative test of potential abuse of the sickness insurance system among men.

Two additional hypotheses are tested. First, a worker who reports sick in order to watch the skiing competition at Oberstdorf might call in sick on Wednesday to convince his employer that he is really sick. There-

\footnotetext{
${ }^{8}$ As an alternative, $\delta$ could be estimated using the probit model. Since each male or female in a specific time period is just a replicate of the other individuals belonging to this group, the contribution of each individual to the likelihood function is identical and a grouped probit model can be estimated.
} 
fore, I also consider two-day cases of illness which started on Wednesday in the analysis.

Second, potential abuse of the sickness insurance system might differ among age groups. Older workers usually have a higher degree of employment protection than younger workers. For example, in Sweden the share of temporary employment contracts is greater among younger workers and it is much easier for an employer not to renew a temporary contract than face the cost of firing a worker on a permanent contract (see Arai \& Skogman Thoursie (2001)). For this reason, older workers might take a smaller risk than younger workers if they abuse the sickness insurance system. If this is the case, the number of older male workers who report sick would be expected to increase to a larger extent than the number of younger men during the sporting events. On the other hand, the work ethic might be positively related to age, implying that the number of young male workers who report sick would increase more relative to older men. To investigate potential behavioral differences among age groups, the difference-in-difference estimator is applied to various age groups. In the analysis of the skiing competition, only two age groups, those aged 20-44 and 45-64, were used. This is because not many workers reported sick on a single Thursday. Regarding the Calgary Games, the age groups 20-34, 35-54, 45-54 and 55-64 were used. ${ }^{9}$

\footnotetext{
${ }^{9}$ In Sweden, school children have a one-week winter break in February or March depending on the child's county of residence. Unfortunately, information on county of residence is not available in the data and the break might coincide with the time period of the sporting event. This is not a problem, however, unless workers report sick to spend time with their children and such behavior differs systematically between men and women. Parents with children of school age are on average in the age group 30-55. If men report sick to spend the break with their children, the estimated effect of the sporting event would not be present for the youngest and the oldest age groups.
} 


\section{Results}

The results from the difference-in-difference estimation of the effect of the Oberstdorf Thursday on the sick rate are reported in Table 1. The top panel compares the change in male sick rates for one-day cases of illness between the Oberstdorf Thursday and the preceding Thursday (first row) with the corresponding change for women (second row). The difference-in-difference estimate is given by the figure in the third row and the last column. The lower panel contains the corresponding figures for two-day sick rates.

Regarding one-day sick rates, the results show an increase in the male sick rate on the Oberstdorf Thursday by 0.58 percentage points. Women, on the other hand, exhibit a decrease in their sick rate between the corresponding periods by 0.39 percentage points. Thus, the difference-indifference estimate of the Oberstdorf effect yields a significant increase in the male sick rate by 0.97 percentage points. There were 1,272 men who reported sick the previous Thursday, implying that the increase in the number of men who reported sick associated with the skiing competition is estimated at approximately 16 percent $(207 / 1,272) .{ }^{10}$ If women reported sick in order to watch the skiing competition on television, the male increase is underestimated (this holds for all estimated effects obtained in this paper).

\section{— Table 1 about here -}

Regarding two-day cases of illness the difference-in-difference estimate of the Oberstdorf Thursday is not significant. Apparently, workers in general are not afraid to report sick for just one day in order to watch the skiing competition and do not stay home a second day to convince

\footnotetext{
${ }^{10}$ The point estimate for the increased number of cases of illness for men is calculated as $(0.000097) \times 2,130,500$.
} 
their employer that they are really sick. ${ }^{11}$ I also estimated the effect of two-day cases which started on Wednesday, but the hypothesis that men report sick on Wednesday to convince their employer that they are indeed ill is not supported by the results.

If the model used to estimate the effect of the Oberstdorf event on reporting sick is correctly specified, there should be no significant difference-in-difference estimate of any Thursday without any popular sporting event. Thus, the key identifying assumption of the estimated model-equation (1) - is that in the absence of the skiing competition, $\delta$ would be zero. Using each of the four Thursdays before and after Oberstdorf as a potential "sports Thursday", with each Thursday in turn as the comparison period, no significant effect should prevail. This yields 72 difference-in-difference estimates (see Table A2 in the Appendix). About 86 percent $(62 / 72)$ of these estimates support the key identifying assumption of the model. Most difference-in-difference estimates show significant coefficients with expected signs when the Oberstdorf Thursday is included and insignificant coefficients for those Thursdays when the Oberstdorf Thursday is not included.

These results clearly indicate an effect of the skiing competition in terms of an increase in the number of men who report sick. Even though this estimated effect seems to be quantitatively small, it should be emphasized that the sporting event took place on a single day. From this perspective, abuse of the sickness insurance system might be a substantial problem if such behavior is present on several occasions during a year.

The results from difference-in-difference estimation of the effect of the winter Olympic Games in Calgary on the sick rate are presented in Table 2. For one-day cases, the male sick rate remains constant between the

\footnotetext{
${ }^{11}$ The effect of the skiing competition was also estimated by the grouped probit model. The results obtained above are confirmed by such an analysis; results are available on request.
} 
Calgary period and the preceding period. Women, on the other hand, exhibit a substantial decrease in their sick rate between the corresponding periods by 11.2 percentage points. If women constitute a suitable comparison group, the number of men who reported sick should have decreased to same extent as women. Thus, the difference-in-difference estimate of the Calgary effect yields a significant increase in the male sick rate by 11.2 percentage points. There were 29,726 men who reported sick during the pre-Calgary period, implying that the increase in one-day cases associated with the Calgary Games is estimated at approximately 8 percent $(2,434 / 29,726){ }^{12}$

In the Calgary analysis, a worker was permitted to report sick for one day within the whole Calgary period instead of only one day as was the case for Oberstdorf. For this reason, the quantitative increase in the number of one-day cases associated with the Calgary games is substantial.

\section{— Table 2 about here -}

As shown in Table 2, the change in the number of men who reported sick during the Calgary Games for two days and up to seven days, there are significant effects for all lengths in the interval between 2.9 and 16.1 percentage points. ${ }^{13}$

The key identifying assumption of the model used to estimate the effects of the Calgary Games is that there should be no significant differencein-difference estimate of a two-week period when no Olympic Games took place. Two two-week periods before as well as two two-week periods after the Calgary Games were used in order to estimate a potential Calgary effect (see Table A3 in the Appendix). Of the 21 difference-in-difference estimates reported, 15 support the identifying assumption of the model.

\footnotetext{
${ }^{12}$ The point estimate for the increased number of cases of illness is calculated as $(0.00112) \times 2,173,200$, where $2,173,200$ is total male employment in the first quarter of 1988 .

${ }^{13}$ Results when when estimating the grouped probit model confirm the results obtained above (available on request).
} 
As a final analysis, the difference-in-difference estimator was applied to different age groups (see Table 3). As the intention here is not to quantify the results, the casual effects were estimated by the grouped probit model. The results clearly show that the causal effect of the Oberstdorf event is only significant for younger workers aged 20-44. As regards the Calgary Games, men in age groups 20-34 and 35-44 significantly changed their behavior with respect to reporting sick in order to watch the Calgary Games but very few significant effects were estimated for the two older age groups. If age is a good indicator of the degree of employment protection, the results show that abuse of the sickness insurance system is not related to employment protection. Instead, it might be the case that the work ethic differs across age groups.

\section{— Table 3 about here -}

To summarize, both sporting events implied a significant increase in the number of men who reported sick. The total increase in sick days associated with the Calgary Games amounts to 43,744 (the quantified effects of both sports events are reported in Table A4 in the Appendix). The average hourly wage rate for men in 1991 was approximately SEK 88. ${ }^{14}$ Based on an eight-hours workday, the daily wage of an average male worker was therefore SEK $704 .{ }^{15}$ Multiplying this figure by 43, 744, the cost of the Calgary Games due to abuse of the sickness insurance system amounts to more than SEK 30 million. This is about 3.6 percent of the total costs for all one-day to seven-day cases of illness reported during the two-week Calgary period. Some workers might have reported sick for more than seven days in order to watch the Calgary Games. An extended analysis might have found a significant increase for eight-day cases and longer.

\footnotetext{
${ }^{14}$ USD 1 is about SEK 10.

${ }^{15}$ The average hourly wage rate and the average daily working time for are from the Swedish Level of Living Survey 1991.
} 


\section{Final remarks}

This paper offers an unusual way to measure the potential existence of moral hazard. The difference in the number of men and women who reported sick between the time period of a popular sporting event and a preceding time period was analyzed in order to test the hypothesis that men report sick so that they can watch the sporting event live, i.e., during regular working time or at night. Difference-in-difference estimations provide clear evidence that younger male workers abused the sickness insurance system.

The possibilities of watching sports on television have grown rapidly in the last few decades. This might have reduced the propensity to abuse the sickness insurance system in the sense that watching sports can now be allocated to different hours, including after work. On the other hand, the greatest pleasure is most likely derived from watching the event live.

The results obtained in this paper show that moral hazard may potentially give rise to a serious problem in the sickness insurance system. If workers abuse the system to watching sports, such behavior might also prevail for other reasons, such as hobbies. The two events considered here were of very short duration. Aggregated over a year and considering various types of events which take place during regular working time, the effects might precipitate considerable losses in production and productivity, as well as substantial costs to the sickness insurance system.

In further research, it would be interesting to study whether abuse of the sickness insurance system is a decreasing function of flexible working hours - if workers could allocate time more freely between working and leisure, the abuse might be less. Another issue concerns the extent to which the sickness benefit level affects abusive behavior. One way to obtain a casual effect of the benefit level on reporting sick would be to use two identical sporting events - one taking place in a year with a one-day waiting period and the other in a year with no waiting period. 
Unfortunately, I have not been able to find such an event. 


\section{References}

Abrahamsson, U. (1990) Are we Nearing the Top of the Hill? Notes from a Decade of Working toward Equality in Swedish Broadcasting. Stockholm: Sveriges Radio, PUB.

Angrist, J. D. \& Lavy, V. (2001), Does Teacher Training Affect Pupil Learning? Evidence from Matched Comparison in Jerusalem Public Schools, Journal of Labor Economics, 19, 343-369.

Arai, M. \& Skogman Thoursie, P. (2001), Incentives and Selection in Cyclical Absenteeism. FIEF Working Paper Series 2001 no. 167, Trade Union Institute for Economic Research, Stockholm.

Ashenfelter, O. (1978), Estimating the Effect of Training Programs on Earnings, Review of Economics and Statistics, 60, 47-57.

Ashenfelter, O. \& Card, D. (1985), Using Longitudinal Structure of Earnings to Estimate the Effect of Training Programs, Review of Economics and Statistics, 67, 648-660.

Barmby, T. A., Orme, C. D. \& Treble, J. G. (1991), Worker Absenteeism: An Analysis using Microdata, Economic Journal, 101, 214-229.

Barmby, T. A., Orme, C. D. \& Treble, J. G. (1995), Worker Absence Histories: A Panel Data Study, Economic Journal, 2, 53-65.

Brown, S. \& Sessions, J. (1996), The Economics of Absence: Theory and Evidence, Journal of Economic Surveys, 10, 23-53.

Brown, S., Fakhfakh, F. \& Sessions, J. (1999), Absenteeism and Employee Sharing: An Empirical Analysis Based on French Panel Data, 1981-1991, Industrial and Labor Relations Review, 52, 234251.

Card, D. (1990), The Impact of the Mariel Boatlift on the Miami Labor Market, Industrial and Labor Relations Review, 43, 245-257.

Card, D. \& Krueger, A. B. (1994), Minimum Wages and Employment: A Case Study of the Fast-Food Industry in New Jersey and Pennsylvania, The American Economic Review, 84, 772-793.

Goldin, C. \& Rouse, C. (2000), Orchestrating Impartiality: The Impact of "Blind" Auditions on Female Musicians, The American Economic Review, 90, 715-741.

Gruber, J. (1996), Disability Insurance Benefits and Labor Supply, NBER Working Paper no. 5866, National Bureau of Economic Research, Cambridge.

Johansson, P. \& Palme, M. (1996), Do Economic Incentives Affect Work Absence? Empirical Evidence using Swedish Micro Data, Journal of Public Economics, 59, 195-218. 
Lidwall, U. \& Skogman Thoursie, P. (2000), Sickness Absence and Disability Pensioning during the Last Decades, in Marklund, S. (ed.), Work Life and Health in Sweden. Stockholm: National Institute for Working Life and National Board of Occupational Safety and Health.

Statistics Sweden (1987), Labor Force Surveys, Statistics Sweden, Stockholm.

Statistics Sweden (1988), Labor Force Surveys, Statistics Sweden, Stockholm.

Meyer, B. D., Viscusi, W. K. \& Durbin, D. L. (1995), Worker's Compensation and Injury Duration: Evidence from a Natural Experiment, The American Economic Review, 85, 322-340.

Winkelmann, R. (1999), Wages, Firm Size and Absenteeism, Applied Economics Letters, 6, 337-341. 


\section{Tables}

Table 1. Difference-in-difference estimates of the effect of the crosscountry skiing competition in Oberstdorf on the sick rate.

\begin{tabular}{lccc}
\hline & Thursday & Thursday & \\
& February 5 & February 12 & \\
& $(1)$ & $(2)$ & $(2)-(1)$ \\
\hline 1 sick day & $5.97^{* * *}$ & $6.55^{* * *}$ & $0.58^{* *}$ \\
Men & $(0.17)$ & $(0.18)$ & $(0.25)$ \\
& $15.03^{* * *}$ & $14.64^{* * *}$ & -0.39 \\
Women & $(0.27)$ & $(0.25)$ & $(0.36)$ \\
& $-9.06^{* * *}$ & $-8.09^{* * *}$ & $0.97^{* *}$ \\
Men-women difference & $(0.32)$ & $(0.31)$ & $(0.45)$ \\
& & & \\
2 sick days & & & \\
Men & $10.64^{* * *}$ & $10.81^{* * *}$ & 0.17 \\
& $(0.21)$ & $(0.22)$ & $(0.30)$ \\
Women & $20.61^{* * *}$ & $20.26^{* * *}$ & -0.35 \\
& $(0.33)$ & $(0.31)$ & $(0.47)$ \\
Men-women difference & $-9.97^{* * *}$ & $-9.45^{* * *}$ & 0.53 \\
& $(0.39)$ & $(0.39)$ & $(0.58)$
\end{tabular}

\section{NOTES:}

i) Bootstrapped standard errors in parentheses (using 200 random samples with replacement).

ii) $*$, ** and $* * *$ denote significantly different from zero at the 10,5 and 1 percent levels.

iii) The sick rates are expressed as shares in percent of employment in hundreds. For example, the male one-day sick rate on the Oberstdorf Thursday is 6.55, implying that 0.0655 percent of employed men reported sick on this Thursday. 
Table 2. Difference-in-difference estimates of the effect of the Calgary Olympic Games on the sick rate.

\begin{tabular}{lccc}
\hline & $\begin{array}{c}\text { 2-week period } \\
\text { before Calgary } \\
(1)\end{array}$ & $\begin{array}{c}\text { 2-week } \\
\text { Calgary period } \\
(2)\end{array}$ & $(2)-(1)$ \\
\hline 1 sick day & $136.8^{* * *}(0.8)$ & $136.9^{* * *}(0.8)$ & $0.1(1.2)$ \\
Men & $261.6^{* * *}(1.2)$ & $250.5^{* * *}(1.1)$ & $-11.2^{* * *}(1.8)$ \\
Women & $-124.9^{* * *}(1.5)$ & $-113.6^{* * *}(1.4)$ & $11.2^{* * *}(2.2)$ \\
Men-women difference & & & \\
2 sick days & $161.7^{* * *}(0.9)$ & $166.6^{* * *}(0.9)$ & $5.0^{* * *}(1.2)$ \\
Men & $250.8^{* * *}(1.1)$ & $239.6^{* * *}(1.1)$ & $-11.2^{* * *}(1.5)$ \\
Women & $-89.1^{* * *}(1.5)$ & $-73.0^{* * *}(1.3)$ & $16.1^{* * *}(2.0)$ \\
Men-women difference & & & \\
3 sick days & $123.0^{* * *}(0.7)$ & $124.1^{* * *}(0.8)$ & $1.1(1.1)$ \\
Men & $160.8^{* * *}(0.8)$ & $151.7^{* * *}(0.8)$ & $-9.2^{* * *}(1.2)$ \\
Women & $-37.9^{* * *}(1.0)$ & $-27.6^{* * *}(1.1)$ & $10.3^{* * *}(1.4)$ \\
Men-women difference & & & \\
4 sick days & $82.8^{* * *}(0.6)$ & $86.5^{* * *}(0.6)$ & $3.7^{* * *}(1.0)$ \\
Men & $99.5^{* * *}(0.7)$ & $95.0^{* * *}(0.7)$ & $-4.6^{* * *}(1.0)$ \\
Women & $-16.7^{* * *}(0.9)$ & $-8.4^{* * *}(0.9)$ & $8.3^{* * *}(1.3)$ \\
Men-women difference & & & \\
5 sick days & $97.0^{* * *}(0.6)$ & $104.1^{* * *}(0.7)$ & $7.2^{* * *}(0.9)$ \\
Men & $103.3^{* * *}(0.7)$ & $101.8^{* * *}(0.7)$ & $-1.6(1.0)$ \\
Women & $-6.4^{* * *}(0.9)$ & $2.4^{* *}(1.0)$ & $8.7^{* * *}(1.4)$ \\
Men-women difference & & & \\
6 sick days & & & \\
Men & $49.1^{* * *}(0.5)$ & $52.9^{* * *}(0.5)$ & $3.8^{* * *}(0.7)$ \\
Women & $49.5^{* * *}(0.5)$ & $50.4^{* * *}(0.5)$ & $1.0(0.7)$ \\
Men-women difference & $-0.4(0.6)$ & $2.5^{* * *}(0.7)$ & $2.9^{* * *}(1.0)$ \\
7 sick days & & & \\
Men & $101.7^{* * *}(0.7)$ & $109.6^{* * *}(0.7)$ & $7.9^{* * *}(1.03)$ \\
Women & $99.5^{* * *}(0.7)$ & $102.7^{* * *}(0.7)$ & $3.2^{* * *}(1.0)$ \\
Men-women difference & $2.2^{* *}(1.0)$ & $6.9^{* * *}(0.9)$ & $4.7^{* * *}(1.4)$ \\
& &
\end{tabular}

NOTES: See Table 1. 
Table 3. Difference-in-difference estimates of the two sporting events for different age groups using the grouped probit model.

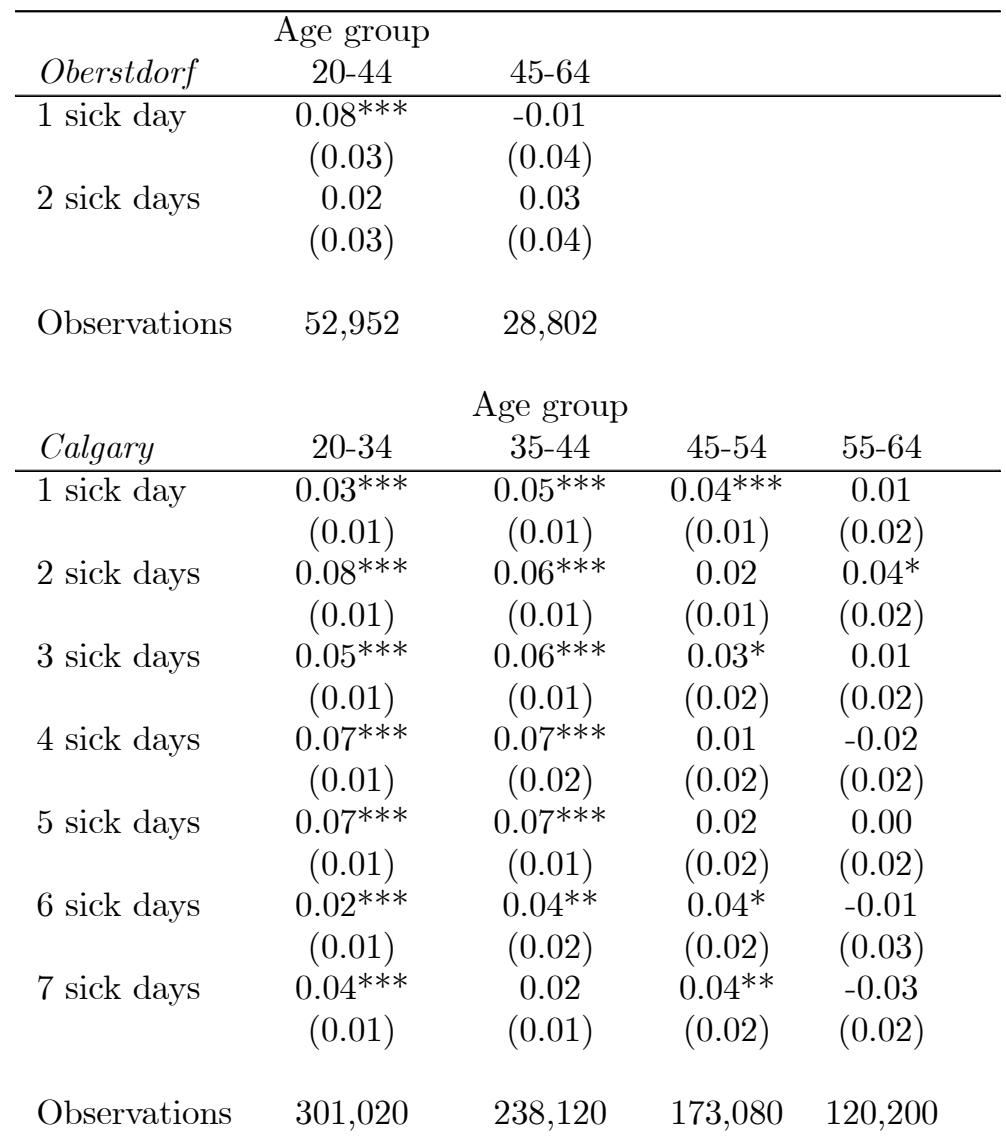

\section{NOTES:}

i) Only the estimated coefficients of the interaction variable between the time dummy for the sporting event and the male dummy (i.e., the difference-in-difference estimate) are reported.

ii) $*$, ** and $* * *$ denote significantly different from zero at the 10,5 and 1 percent levels.

iii) The number of observations for each age group is equal among all models using different numbers of sick days. This is because those under risk of reporting sick, i.e., the employed, are the same in each age group. 


\section{Appendix}

Table A1. Sample statistics for the population of cases of illness beginning on the Oberstdorf Thursday and the pre-Oberstdorf Thursday in 1987, and the two-week Calgary period and the two-week pre-Calgary period in 1988.

\begin{tabular}{lcc}
\hline & $\begin{array}{c}\text { Men } \\
\text { Mean }\end{array}$ & $\begin{array}{c}\text { Women } \\
\text { Mean }\end{array}$ \\
\hline $\begin{array}{l}\text { Oberstdorf } \\
\text { Age }\end{array}$ & $37.5(11.0)$ & $37.9(11.0)$ \\
$\begin{array}{l}\text { Distribution of sick days } \\
\text { day }\end{array}$ & $0.42(3,344)$ & $0.47(6,832)$ \\
2 days & $0.58(4,701)$ & $0.53(7,833)$ \\
& & \\
Empl. February 1987 & $2,130,500$ & $1,957,500$ \\
& & \\
Calgary games & & \\
Age & $36.8(11.4)$ & $37.4(11.6)$ \\
Distribution of sick days & & \\
1 day & $0.18(59,467)$ & $0.25(101,860)$ \\
2 days & $0.21(71,345)$ & $0.24(97,548)$ \\
days & $0.16(53,712)$ & $0.16(62,172)$ \\
4 days & $0.11(36,805)$ & $0.10(38,683)$ \\
5 days & $0.13(43,705)$ & $0.10(40,792)$ \\
days & $0.07(22,178)$ & $0.05(19,877)$ \\
days & $0.14(45,937)$ & $0.10(40,227)$ \\
& & \\
Empl. 1st Quarter 1988 & $2,173,200$ & $1,989,000$
\end{tabular}

\section{NOTES:}

i) Standard deviations and the total number of cases of illness in parentheses.

ii) The employment figures are from Labor Force Surveys, Statistics Sweden (1987). The female labor-force participation rate in the first quarter of 1987 was 80.2 percent (84.8 for men). 
Table A2. Grouped probit difference-in-difference estimates of Thursday effects in 1987 using four pre-Oberstdorf and four post-Oberstdorf Thursdays.

\begin{tabular}{|c|c|c|c|c|c|c|c|c|c|}
\hline & -4 & -3 & -2 & -1 & Ob. & +1 & +2 & +3 & +4 \\
\hline \multirow[t]{2}{*}{-4} & - & -0.02 & -0.01 & 0.01 & $-0.05^{* *}$ & 0.02 & -0.03 & 0.00 & 0.01 \\
\hline & - & $(0.02)$ & $(0.02)$ & $(0.03)$ & $(0.02)$ & $(0.03)$ & $(0.03)$ & $(0.02)$ & $(0.03)$ \\
\hline \multirow[t]{2}{*}{-3} & 0.02 & - & 0.01 & 0.03 & -0.04 & 0.03 & -0.01 & 0.02 & 0.03 \\
\hline & $(0.03)$ & - & $(0.02)$ & $(0.02)$ & $(0.02)$ & $(0.03)$ & $(0.03)$ & $(0.02)$ & $(0.03)$ \\
\hline \multirow[t]{2}{*}{-2} & 0.01 & -0.01 & - & 0.02 & $-0.04^{*}$ & 0.03 & -0.02 & 0.01 & 0.02 \\
\hline & $(0.02)$ & $(0.02)$ & - & $(0.02)$ & $(0.02)$ & $(0.02)$ & $(0.02)$ & $(0.02)$ & $(0.02)$ \\
\hline \multirow[t]{2}{*}{-1} & -0.01 & -0.03 & -0.02 & - & $-0.06^{* * *}$ & -0.01 & $-0.04^{*}$ & -0.01 & -0.00 \\
\hline & $0.03)$ & $(0.02)$ & $(0.02)$ & - & $(0.02)$ & $(0.03)$ & $(0.03)$ & $(0.02)$ & $(0.02)$ \\
\hline \multirow[t]{2}{*}{ Ob. } & $0.05^{* *}$ & 0.04 & $0.04^{*}$ & $0.06^{* * *}$ & - & $0.07^{* * *}$ & 0.02 & $0.05^{* *}$ & $0.06^{* * *}$ \\
\hline & $(0.02)$ & $(0.02)$ & 0.02 & $(0.02)$ & - & $(0.02)$ & $(0.02)$ & $(0.02)$ & $(0.02)$ \\
\hline \multirow[t]{2}{*}{+1} & -0.02 & -0.03 & -0.03 & -0.01 & $-0.07^{* * *}$ & - & $-0.05^{*}$ & -0.02 & -0.01 \\
\hline & $(0.03)$ & $(0.03)$ & $(0.02)$ & $(0.03)$ & $(0.03)$ & - & $(0.03)$ & $(0.03)$ & $(0.03)$ \\
\hline \multirow[t]{2}{*}{+2} & 0.03 & 0.01 & 0.02 & $0.04^{*}$ & -0.02 & $0.05^{*}$ & - & 0.03 & $0.04^{*}$ \\
\hline & $(0.03)$ & $(0.03)$ & $(0.02)$ & $(0.03)$ & $(0.02)$ & $(0.03)$ & - & $(0.03)$ & $(0.03)$ \\
\hline \multirow[t]{2}{*}{+3} & 0.00 & -0.02 & -0.01 & 0.01 & $-0.05^{* *}$ & 0.02 & -0.03 & - & 0.01 \\
\hline & $(0.03)$ & $(0.02)$ & $(0.02)$ & $(0.02)$ & $(0.02)$ & $(0.03)$ & $(0.03)$ & - & $(0.02)$ \\
\hline \multirow[t]{2}{*}{+4} & -0.01 & -0.03 & -0.02 & 0.00 & $-0.06^{* * *}$ & 0.01 & $-0.04^{*}$ & -0.01 & - \\
\hline & $(0.03)$ & $(0.03)$ & $(0.02)$ & $(0.02)$ & $(0.02)$ & $(0.03)$ & $(0.03)$ & $(0.02)$ & - \\
\hline
\end{tabular}

\section{NOTES:}

i) Only coefficient estimates representing the difference-in-difference estimates are reported. Standard errors in parentheses.

ii) *, ** and $* * *$ denote significantly different from zero 10,5 and 1 percent levels.

iii) All estimations include the male dummy as well as a Thursday dummy variable.

iv) Ob. denotes the Oberstdorf Thursday, -1 the Thursday before Oberstdorf, +1 is the Thursday after Oberstdorf, and so on.

$v$ ) The table should be read in the following way: the estimated coefficient in column 1 , row 2 is the difference-in-difference estimate of the increase in males who reported sick on the Thursday three weeks before and the Thursday four weeks before Oberstdorf. 
Table A3. Grouped probit difference-in-difference estimates of the effect of different two-week periods in 1988.

\begin{tabular}{lccc}
\hline & Calgary (-1) & Calgary & Calgary $(+2)$ \\
& Calgary (-2) & Calgary (-1) & Calgary $(+1)$ \\
\hline 1 sick day & $0.016^{* *}$ & $0.035^{* * *}$ & -0.010 \\
& $(0.006)$ & $(0.006)$ & $(0.006)$ \\
2 sick days & -0.003 & $0.056^{* * *}$ & $-0.020^{* * *}$ \\
& $(0.006)$ & $(0.006)$ & $(0.006)$ \\
3 sick days & -0.001 & $0.044^{* * *}$ & -0.009 \\
& $(0.0071)$ & $(0.007)$ & $(0.007)$ \\
4 sick days & 0.001 & $0.051^{* * *}$ & $-0.024^{* * *}$ \\
& $(0.008)$ & $(0.008)$ & $(0.008)$ \\
5 sick days & 0.006 & $0.049^{* * *}$ & -0.008 \\
& $(0.008)$ & $(0.007)$ & $(0.008)$ \\
6 sick days & 0.011 & $0.027^{* * *}$ & $-0.017^{*}$ \\
& $(0.009)$ & $(0.009)$ & $(0.009)$ \\
7 sick days & $0.016^{* *}$ & $0.025^{* * *}$ & $-0.014^{*}$ \\
& $(0.008)$ & $(0.007)$ & $(0.007)$
\end{tabular}

\section{NOTES:}

i) Standard errors in parentheses.

ii) $*, * *$ and ${ }^{* * *}$ denote significantly different from zero at the 10,5 and 1 percent levels.

iii) Column 1 shows the two-week pre-Calgary period as the investigation period, column 2 the Calgary effects and column 3 the two-week period effect using two periods after Calgary as the investigation period. 
Table A4. Quantified effects of the two sporting events based on the point estimates from the difference-in-difference estimations.

\begin{tabular}{|c|c|c|c|c|}
\hline & $\begin{array}{c}\text { Males reported sick } \\
\text { period before } \\
\text { (1) }\end{array}$ & $\begin{array}{l}\text { Event } \\
\text { effects } \\
(2) \\
\end{array}$ & $\begin{array}{c}\text { Percent } \\
(2) /(1) \\
\end{array}$ & $\begin{array}{l}\text { Sick days } \\
(2) \times \text { length }\end{array}$ \\
\hline \multicolumn{5}{|c|}{$\begin{array}{l}\text { World Championship in } \\
\text { Oberstdorf }\end{array}$} \\
\hline 1 sick day & 1,272 & 207 & 16.2 & 207 \\
\hline 2 sick days & 2,266 & 113 & 5.0 & 226 \\
\hline Total & 3,538 & 320 & - & 433 \\
\hline \multicolumn{5}{|c|}{ Calgary Olympic Games } \\
\hline 1 sick day & 29,726 & 2,434 & 8.2 & 2434 \\
\hline 2 sick days & 35,132 & 3,499 & 10.0 & 6998 \\
\hline 3 sick days & 26,732 & 2,238 & 8.4 & 6714 \\
\hline 4 sick days & 17,997 & 1,804 & 10.0 & 7216 \\
\hline 5 sick days & 21,074 & 1,891 & 9.0 & 9455 \\
\hline 6 sick days & 10,671 & 630 & 5.9 & 3780 \\
\hline 7 sick days & 22,108 & 1,021 & 4.6 & 7147 \\
\hline Total & 163,440 & 13,517 & - & 43,744 \\
\hline
\end{tabular}

